\title{
EM BUSCA DA INTEGRALIDADE NO ATENDIMENTO À VIO- LÊNCIA SEXUAL A CRIANÇAS E ADOLESCENTES: REFLEXÕES A PARTIR DA REALIDADE DOS CREAS TOCANTINENSES
}

IN SEARCH OF INTEGRALITY CARE IN SEXUAL VIOLENCE TO CHILDREN AND ADOLESCENTS: REFLECTIONS FROM THE REALITY OF CREAS TOCANTINS

\section{Monique Soares Vieira ${ }^{1}$}

RECEBIDO EM: 06/09/2017 / APROVADO EM: 15/10/2017

DOI: $10.5902 / 2317175825440$

\section{RESUMO}

O presente artigo versa sobre a construção da integralidade do atendimento às crianças, aos adolescentes e às suas famílias em situação de violência sexual, por meio da articulação do Centro de Referência Especializado de Assistência Social (CREAS) com a rede de proteção. Para a coleta de dados, realizaram-se 17 entrevistas com famílias, profissionais e coordenadores/as de 5 CREAS, esses dados foram submetidos à análise de conteúdo. Os resultados revelam um cenário em que há predominância de ações fragmentadas, focalizadas, imediatistas e acríticas, que atuam como vetores para a revitimização das crianças, adolescentes e famílias, e não rompem com o padrão hegemônico das respostas do Estado. Assim concluímos que a construção da integralidade do atendimento requer um processo de mudança que não depende somente dos/as profissionais, mas sim de todos os sujeitos que atuam na rede de proteção e tal movimento exige urgentemente a ruptura com concepções conservadoras e particularistas.

Palavras-Chave: Violência Sexual; Criança e Adolescente; Integralidade.

\footnotetext{
1 Professora do curso de Serviço Social da Universidade Federal do Pampa. Mestre (2013) e Doutora (2015) em Serviço Social pela Pontifícia Universidade Católica do Rio Grande do Sul. Graduada em Serviço Social pela Universidade Federal do Pampa (2010). Pesquisadora do Núcleo de Estudos e Pesquisas em Ética, Violência e Direitos Humanos (NEPEVEDH/PUCRS). Pós-Graduada em Impactos da Violência na Saúde pela Fundação Oswaldo Cruz (FIOCRUZ). Atuou como membro do Comitê de Ética em Pesquisa da Universidade Federal do Tocantins. Tem experiência na área da Política de Assistência Social, atuando principalmente nos seguintes temas: violência sexual, criança e adolescente, medidas socioeducativas em meio aberto, família e expressões da violência contra a mulher e idoso. E-mail: moniquevieira@unipampa.edu.br.
} 
EM BUSCA DA INTEGRALIDADE NO ATENDIMENTO À VIOLÊNCIA SEXUAL A CRIANÇAS E ADOLESCENTES:

REFLEXÕES A PARTIR DA REALIDADE DOS CREAS TOCANTINENSES

\begin{abstract}
In order to improve basic health care issues, such as the lack of doctors in hospital units, especially in the countryside cities of the states, the government has created a program called Mais Medicos Program (MMP), focused on the recruitment of professionals from different nationalities, outpatient clinic at critical points. In this context, the purpose of this study was highlighting the impacts on the basic health of Pernambuco after its implementation. The research data were collected from the DATASUS website, specifically regarding information of the medical consultation number, number of deaths due to preventable causes, number of hospitalizations and values for hospital services. A chi-square test was used and a linear regression model was used to infer the relationship between the number of deaths in the State of Pernambuco (dependent variable) and the medical consultation number (independent variable). The results showed that only $26.59 \%$ of the changes in the number of deaths are explained by the variations in the medical consultation number and in a qualitative analysis using a dummy variable, it was observed that there is no difference between the average expected value of the number of deaths before and after the adoption of the program. Therefore, it can be inferred that the variable medical consultation number showed statistically significant in front of the collected data.
\end{abstract}

Keywords: Basic Health; SUS; Most Medical Program.

\title{
1 Introdução
}

As discussões presentes neste artigo buscam apreender as particularidades do enfrentamento à violência sexual infanto-juvenil, no estado de Tocantins, a partir das ações que são desenvolvidas pelos cinco' ${ }^{1}$ CREAS pesquisados. $O$ desafio presente neste estudo fora capturar a essencialidade do atendimento que atualmente vem sendo ofertado não somente às crianças e aos adolescentes em situação de violência sexual, mas, sobretudo às suas famílias.

Por ser um fenômeno de múltiplas faces e recoberto por mitos e tabus, o enfrentamento à violência sexual para os/as profissionais entrevistados/as requer um trabalho articulado, em que os sujeitos sociais ampliem os espaços para a discussão, reconhecendo as limitações de cada instituição, mas, principalmente, estabelecendo uma relação dialógica para identificar as possibilidades, organizando, desse modo, respostas efetivas no âmbito da atenção às crianças, aos adolescentes e às famílias.

O percurso teórico-metodológico de análise da atuação dos CREAS tocantinenses às situações de violência sexual contra crianças e adolescentes vem revelando um cenário de diversos desafios e obstáculos que precisam ser ultrapassados para a promoção da integralidade do atendimento. As falas dos sujeitos entrevistados evidenciam a existência de um longo e árduo caminho para a efetivação dos direitos humanos dessa população. Ações incipientes, imediatas e emergenciais têm sido a tônica da atenção prestada pelo Serviço de Atendimento Especializado a Famílias e Indivíduos (PAEFI) às vitimizações sexuais envolvendo crianças e adolescentes.

1 Os municípios que participaram da presente pesquisa foram: Dianópolis, Gurupi, Miranorte, Palmas e Paraíso do Tocantins. 
Em uma análise superficial e valorativa, buscam-se somente os/as responsáveis pela inefetividade das ações. No entanto, em uma análise mais profunda e crítica da realidade, percebe-se que são diversos os obstáculos a serem superados, que envolvem aspectos que transcendem os processos interventivos dos/as profissionais do PAEFI.

As condições estruturais, econômicas e políticas são luminares para se refletir sobre o enfrentamento à violência sexual no âmbito da Política de Assistência Social e, principalmente, dos seus rebatimentos nas relações e condições de trabalho dos/as profissionais do CREAS. Tal relação é dialética: precarização das políticas sociais - exercício profissional - atendimento aos/às usuários/as e, tem-se conformado como um desafio constante a ser enfrentado, e a partir disso apontar para a construção de caminhos metodológicos que possibilitem a integralidade no atendimento às situações de violência sexual infanto-juvenil.

A integração das políticas sociais do Sistema de Garantia de Direitos (SGD) depende da elaboração de metodologias (fluxos e protocolos) capazes de fortalecer a articulação entre os serviços e possibilitar a efetivação de uma Política de Proteção aos direitos humanos das crianças e adolescentes, essencialmente, no âmbito dos municípios.

A consolidação dessa Política Municipal de Proteção requer não somente a disponibilidade de serviços, ainda que isso seja fundamental, mas também a garantia da qualidade de tais ações. $O$ atendimento especializado numa perspectiva de integralidade, que apreenda os sujeitos na sua totalidade, requer a constituição de uma rede de atenção capaz de acolher, escutar e proteger, prevenindo revitimizações.

Nesse sentido, o presente artigo assume um compromisso ético-político ao refletir sobre a realidade dos CREAS no Estado do Tocantins e produzir conhecimentos que contribuam para o fortalecimento desse serviço. Os procedimentos metodológicos do estudo serão abordados no próximo item.

\section{Caminho Metodológico do Estudo}

O Sistema Único de Assistência Social (SUAS) no Estado do Tocantins vem sendo implementado desde 2005, entretanto, no que se refere aos serviços da proteção social especial de média complexidade, em especial, a constituição dos Centros de Referência Especializado de Assistência Social, dos 139 municípios apenas 22 possuem CREAS, ficando o restante dos municípios descobertos pela proteção social especial. Além disso, no que tange às Delegacias Especializadas à Criança e ao Adolescente, o Estado apresenta somente uma unidade, localizada na capital do Tocantins, Palmas.

A análise da realidade dos CREAS tocantinenses fora norteada pelo método dialético-crítico a partir de quatro categorias: historicidade, totalidade, contradição e mediação, que possibilitaram apreendê-la como sendo um processo "histórico, dotado de materialidade e movido pela contradição: afir- 
EM BUSCA DA INTEGRALIDADE NO ATENDIMENTO À VIOLÊNCIA SEXUAL A CRIANÇAS E ADOLESCENTES: REFLEXÕES A PARTIR DA REALIDADE DOS CREAS TOCANTINENSES

mação-negação-nova afirmação" (MEKSENAS, 2002, p.88). Para a coleta de dados, realizaram-se entrevistas com aplicação de um formulário, contendo perguntas abertas com 17 sujeitos: (05) coordenadores, (05) assistentes sociais e (05) psicólogos de 5 CREAS e, com (02) famílias que possuíam crianças/ adolescentes em atendimento na referida instituição.

Para a escolha dos sujeitos que participaram da pesquisa, levou-se em consideração o seguinte aspecto: os sujeitos deveriam ser coordenadores/as e profissionais vinculados/as aos CREAS e ao Serviço de Proteção e Atendimento Especializado a Famílias e Indivíduos (PAEFI) dos cinco municípios, na perspectiva de trazer à luz os desafios presentes nas ações destinadas às crianças, aos adolescentes e suas famílias em situação de violência sexual. Também compuseram a amostra famílias atendidas pelo PAEFI (situações de violência sexual), com a finalidade de desvendar a realidade em que as crianças e adolescentes e seus familiares vivenciam diante das expressões da violência (as percepções, as dificuldades, o acesso à rede de proteção, etc.).

As entrevistas aconteceram mediante a articulação com as equipes técnicas, que indicaram as famílias que iriam participar do estudo. Salienta-se que foram encontradas diversas dificuldades nesse processo, pois de acordo com os/as profissionais as famílias não demonstraram interesse em colaborar com a pesquisa. Dessa forma, não houve um contato prévio da pesquisadora com estas para esclarecimentos sobre as entrevistas, o que fora considerado um elemento obstaculizador. Nesse sentido, respeitou-se o posicionamento desses sujeitos, entrevistando-se assim apenas duas mães.

No formulário, constaram perguntas com a finalidade de obter uma maior apreensão acerca da configuração da violência sexual, bem como a percepção que os sujeitos possuem sobre esse fenômeno e como vêm sendo desenvolvidas as ações para a proteção das crianças e adolescentes e para a prevenção às situações de violência sexual. Optou-se, no formulário, por questões abertas, pois estas, diferentemente das perguntas fechadas que possibilitam apenas um conhecimento superficial da realidade,s permitem um nível de profundidade durante o diálogo. Nesse sentido, esse estilo de perguntas contribuiu para uma apreensão mais ampla da vivência dos sujeitos entrevistados no enfrentamento à violência sexual, proporcionando-lhes maior liberdade de resposta e interação no momento da entrevista.

Para analisar os dados coletados na pesquisa, optou-se pela técnica de análise de conteúdo de Bardin (1977). A análise das ações ofertadas pelos CREAS às crianças, adolescentes e suas famílias fora realizada a partir de uma perspectiva histórica, social, crítica e de totalidade dos elementos que permeiam a sua incidência na sociedade contemporânea, visando contribuir com subsídios teóricos para a apreensão desse fenômeno como expressão da questão social. A pesquisa foi aprovada pela comissão científica da Unidade acadêmica e pelo Comitê de Ética em Pesquisa sob o número do protocolo CAEE 31121214.2.0000.5336, respeitando todos os princípios éticos que regem a pesquisa conforme resolução 466/2012 do Conselho Nacional de Ética em Pesquisa, CONEP. 


\section{Os Desafios do Atendimento Especializado às Crianças e Adolescentes em Situação de Violência Sexual no Tocantins}

Os desafios em construir uma reflexão acerca do atendimento ofertado à população infanto-juvenil que sofre vitimização sexual são muitos, dentre eles destaca-se: a não generalização das singularidades; o estabelecimento de mediações teórico-práticas que possibilitem não somente a apreensão no nível teórico, mas que se transmutem em possibilidades de reflexão mediata sobre os processos interventivos, a interpretação ética das informações de modo a comportar uma aproximação com a realidade dos (as) entrevistados (as) e, principalmente, contribuir para construção de estratégias metodológicas a partir da interdisciplinaridade e da intersetorialidade, visando à integralidade no atendimento.

A materialização da integralidade do atendimento para os/as entrevistados/as requer um movimento mais amplo que abranja também os/as gestores/as da Política de Assistência Social, desconstruindo concepções arcaicas que ainda sondam a operacionalização da assistência social no Tocantins.

Diante disso, os/as profissionais percebem que a construção de uma rede de proteção deve balizar a mudança da cultura política tocantinense em que "as famílias devem assumir a centralidade que a PNAS propõe, temos que chamar elas mais para perto do CREAS, envolver mesmo nos atendimentos, romper com a violência no seu interior" (P3D). Os/as profissionais expõem a importância de transformar a persistente e atual cultura política do clientelismo em uma cultura política dos direitos e da cidadania, referendando uma maior visibilidade das ações do CREAS para a população.

Ao enfatizarem que os primeiros passos para a construção de uma política de proteção iniciam-se com o conhecimento e respeito do trabalho social do CREAS, pelas demais políticas sociais e instituições que compõem o SGD, os/as entrevistados/as reafirmam que a consolidação de uma atuação em rede para o enfrentamento à violência requer vontade coletiva que supere práticas subjetivistas e solidifique o compromisso ético e político com a transformação das condições opressoras e violadoras dos direitos das crianças e adolescentes.

Trabalhar em rede, buscando materializar a interdisciplinaridade e a intersetorialidade como premissas do trabalho social de enfrentamento à violência sexual, exige "reconhecer que todos os indivíduos e organizações são dotados de recursos, de capacidades, de possibilidades e que, também, são possuidoras de fragilidades, de carências e limitações" (MOTTI; SANTOS, 2010, p.109).

Mas afinal, por que trabalhar em rede para enfrentar as vitimizações sexuais contra crianças e adolescentes? São múltiplas as respostas que elucidam a importância dessa forma de gestão e execução de ações, essencialmente, no que diz respeito à prevenção da revitimização das crianças, adolescentes e famílias. Trabalhar em rede possibilita aos sujeitos sociais ampliar o olhar sobre as situações de violência sexual, criar fluxos de atenção que tenham um alcance mais efetivo às famílias. Ou seja, a atuação em rede oferece uma orga- 
EM BUSCA DA INTEGRALIDADE NO ATENDIMENTO À VIOLÊNCIA SEXUAL A CRIANÇAS E ADOLESCENTES: REFLEXÕES A PARTIR DA REALIDADE DOS CREAS TOCANTINENSES

nização sócio-institucional com maior dinamismo, mobilização e legitimidade, rompendo com a burocratização das práticas institucionais.

As ações são elaboradas, executadas e avaliadas de forma conjunta e articulada e não isoladamente, evitando-se assim ações fragmentadas com pouca repercussão na vida das famílias. $\mathrm{O}$ trabalho em rede para a proteção dos direitos das crianças e adolescentes está previsto no artigo 86 do Estatuto da Criança e do Adolescente (ECA) que estabelece um "[...] conjunto articulado de ações governamentais, não-governamentais, da União, dos Estados e dos Municípios".

A rede de proteção é composta por agentes governamentais e não-governamentais, e sua organização deve primar para potencializar o controle social por meio dos Conselhos, Conferências, Comitês e Fóruns, fomentando a participação da sociedade civil e da comunidade local. A importância dessa forma de trabalho social consiste na sua constante busca pela não revitimização, prevenindo estigmas e traumas que contribuem para a perpetuação do ciclo da violência.

O fortalecimento da intersetorialidade entre as principais políticas sociais do SGD responsáveis pelo atendimento às crianças e adolescentes (Assistência Social, Educação e Saúde) é uma estratégia mediata para romper-se com a pseudo-aparência construída por alguns/algumas profissionais que não denunciam a violência sexual por não conseguirem visualizar, ou mesmo, desconhecem a atenção que é prestada pela rede de proteção às crianças e adolescentes.

Diante disso, reitera-se que a integralidade do atendimento à violência sexual, por meio da interdisciplinaridade e da intersetorialidade, visa transformar práticas desconexas em processos interventivos integralizados e concretos em que se estabelecem relações sócio-institucionais comprometidas com a proteção dos direitos das crianças e adolescentes. Portanto, para a efetivação da integralidade deve-se reconhecer que "a complexidade da realidade social exige um olhar que não se esgota no âmbito de uma única política social" (JUNQUEIRA, 2004, p.25).

Ao retomar as falas dos/as entrevistados/as é interessante salientar que, ainda que os sujeitos tivessem referido dificuldades para efetivar a intersetorialidade entre as políticas sociais do SGD e terem a percepção de que isto acarreta em ações fragmentadas e com o impacto social muito aquém do esperado, em nenhum momento, elucidaram que esse processo pode provocar a revitimização das crianças, adolescentes e famílias.

As possibilidades do acometimento da revitimização das famílias têm implicações diretas com a violência institucional, entendida por Minayo (2007) como sendo aquela que acontece nas instituições de prestação de serviços como hospitais, unidades de saúde, escolas, abrigos, delegacias, Judiciário, entre outras. Essa expressão da violência é cometida por sujeitos que deveriam promover a proteção às crianças, adolescentes e famílias e lhes garantir um atendimento humanizado.

O trecho extraído da entrevista realizada com a família de uma criança abusada sexualmente e atendida pelo CREAS revela o processo de revitimização: 
A minha filha me contou sobre o que tinha acontecido, não sabia como agir então conversei com uma vizinha que é minha amiga, ela me disse pra chamar a polícia, 'liga pro 190', eu liguei e a polícia veio. Perguntaram o que tinha acontecido falei que ela tinha sofrido abuso sexual de um menino que mora aqui perto, é um adolescente. Então a polícia disse que ia atrás dele e chamou o Conselho Tutelar [...] mas não explicaram direito como ia ser, só que ela ia ser atendida em Palmas. [...] depois a polícia chegou de novo aqui em casa, já era de noite, disseram que iam ter que nos levar pra Palmas para minha menina fazer o exame no IML, quando eu entrei no carro da polícia, dei de cara com ele e com a avó. Minha menina entrou em choro, porque a gente ia ter que ir até Palmas no mesmo carro. Foi horrivel, na frente foram dois policiais, atrás, eu, minha filha, o menino que abusou dela e a avó dele. Foi muito ruim, porque a avó dele começou a dizer que minha filha era mentirosa e que tinha se mostrado pra ele, foi a viagem mais longa da minha vida. (FAMíLIA A).

O relato do/a responsável pela criança que sofreu abuso sexual é impactante, pois além de não terem sido informados sobre os procedimentos para o atendimento e os direitos da criança, a situação descrita é culminante de violência institucional e de revitimização dessa criança e sua responsável. Para Nordenstahl (2008), existem dois níveis de vitimização: a primária e a secundária. A vitimização primária é resultante da ação da violência sexual e possui diversos impactos - físico, psicológico, social, etc. Entretanto, a vitimização secundária ou a revitimização para o autor é caracterizada pelo impacto das intervenções das instituições e seus/suas profissionais.

A revitimização se expressa em intervenções inadequadas, constrangedoras e invasivas que não garantem os direitos das crianças, adolescentes e famílias. O despreparo técnico e não raro o desconhecimento da legislação destinada a essa população, em especial as situações de violência sexual, tem sido os propulsores para a oferta de um atendimento distante da perspectiva de humanização e integralidade.

Melo (2014, p.105), ao refletir sobre a revitimização das crianças nos serviços públicos, principalmente, nas Delegacias, Judiciário e Conselhos Tutelares, refere que "tudo isto faz com que as vítimas se sintam desprotegidas, sem respeito, frustradas, peças de uma engrenagem à qual não pertencem".

Ao considerar o acometimento da violência institucional é preciso ressaltar que ela se manifesta tanto na ação quanto na omissão, ou seja, a ausência de oferta de serviços de qualidade comprometidos com o enfrentamento à violência sexual também se caracteriza como uma violência institucional. A violência institucional manifesta-se ao negligenciar o cuidado e atenção necessários para o atendimento das necessidades objetivas e subjetivas das crianças e adolescentes.

Existe ainda um hiato entre os direitos garantidos às crianças e adolescentes em situação de violência sexual e a realidade dos serviços destinados à sua atenção. Essa lacuna é evidenciada em todos os momentos pelos/as profis- 
EM BUSCA DA INTEGRALIDADE NO ATENDIMENTO À VIOLÊNCIA SEXUAL A CRIANÇAS E ADOLESCENTES: REFLEXÕES A PARTIR DA REALIDADE DOS CREAS TOCANTINENSES

sionais que veladamente, em seus discursos, denunciam a omissão do Estado em ofertar uma atenção qualificada a essa população.

O relato da entrevista revela que a violência institucional, ainda que invisibilizada, ela acontece no cotidiano institucional caracterizada pela omissão do Poder Público.

Eu acho que a rede falha muito, por exemplo, agora de manhã eu atendi um caso que chegou pra cá, onde há uma disputa de guarda, a mãe abandonou a filha e a filha foi morar com a avó paterna junto com o genitor, a mãe apareceu do nada e agora quer a menina e a avó está desesperada porque foi ela quem criou a menina a vida inteira, só que a mãe meio que comprou a criança. Então a criança está sem saber, se quer a mãe, se quer a avó. Então assim não é um caso meu, não tem nada a ver com que eu atendo aqui, e eu não sei pra onde eu vou mandar ela, então eu acho que a rede falha muito com isso. Então assim não é um caso meu, não tem nada a ver com que eu atendo aqui e eu não tendo pra onde mandar, não tenho, eu acho que deveria ter sim outros meios, outros órgãos, que fizessem esse tipo de atendimento, existe policlínica [...] Existe! A policlínica está com uma fila de sei lá 4 meses de espera, [...] unidade de saúde nem todas fazem atendimento psicológico. Hoje mesmo eu não sei te falar uma que está fazendo. Então o que eu vou fazer com ela, eu vou encaminhar ela pro CRAS, onde ela vai fazer grupo de família, reintegração familiar, reintegração de vínculos familiares com essa família é o que eu tenho para oferecer pra ela hoje, então eu acho que deveria sim, os órgãos deveriam olhar mais pra esse lado, eu acho que falha. (P1A).

O trecho da entrevista expressa a omissão do Estado diante das questões que envolvem a proteção das crianças e adolescentes no Tocantins. A ausência de serviços e a não ampliação da oferta dos existentes têm implicações que resultam para o não atendimento das necessidades das famílias. A falta de serviços sociais públicos corrobora também para o aumento das demandas do CREAS, sobrecarregando a equipe técnica e inviabilizando o planejamento e avaliação coletiva das intervenções.

Afirma-se categoricamente que a integralidade do atendimento também diz respeito à oferta de serviços sociais públicos de qualidade à população, evitando-se um trabalho superficial, individualizado e hierárquico:

A fragmentação das políticas públicas, além de fortalecer as hierarquias e os poderes políticos, acarreta na fragilização e, consequentemente, na revitimização das crianças e adolescentes. As políticas públicas em seu modus operandi, privilegiam a centralização de ações e informações, não ampliando seu olhar para a complexidade da violência sexual na vida das crianças e adolescentes. A fragmentação da atenção obstaculiza o acesso aos direitos, pois focaliza-se em ações paliativas e pontuais, não conseguindo concretizar ações conjuntas para a construção de redes municipais. (VIEIRA, 2013, p.101-102). 
Salienta-se que trabalhar em rede não significa ter apenas o conhecimento para qual instituição ou serviço encaminhar os/as usuários/as, significa caminhar junto, acolher as crianças, adolescentes e suas famílias na integralidade, buscando atender suas necessidades básicas, articular e partilhar conhecimentos.

As entrevistas são bastante esclarecedoras nesse sentido, pois os/as profissionais referem que são raras às vezes em que há um compartilhamento de informações ou momentos de interação entre os/as profissionais que compõem a rede de proteção, "é muito difícil o pessoal sentar e conversar sobre um caso, isso acontece dentro do CREAS, com a nossa equipe, mas não com as outras, eu não estou dizendo que não acontece, acontece, mas é difícil". (P3D).

A formação de uma rede, para Santos \& Araújo (2009, p.187), "não deve se restringir aos ajustes técnicos, metodológicos e administrativos, mas implica mudanças culturais, comportamentais". Isso significa que não basta um conjunto de procedimentos e instituições, é preciso transformar as proposições institucionais em ações coletivas e integradas partir de princípios de cooperação, reconhecimento do outro, descentralização e horizontalidade nas relações (SANTOS; ARAÚJO, 2009).

Por isso, a atuação em rede exige a sensibilização dos/as gestores/as e profissionais, o compromisso ético e político, a vontade coletiva, a dinamicidade, e o fortalecimento das redes de apoio informal (família, vizinhos, amigos, etc.), considerando que somente com a construção de objetivos comuns, a definição de competências e papéis e o reconhecimento das limitações e potencialidades de cada instituição, será possível construir ações conjuntas e assim formar e concretizar uma rede de proteção.

Além disso, o atendimento à população infanto-juvenil, que é acometida pela violência sexual, deve ultrapassar a atenção clínica e abranger os demais aspectos e fatores que envolvem essa violência, pois "a criança terá seu desenvolvimento e sua subjetividade definida a partir da realidade concreta na qual esta vive" (SANTIAGO; MATTIOLI, 2009, p.22).

Desse modo, ressalta-se a importância de se considerar as particularidades sociais, econômicas e culturais da criança e sua família, visando a constituição de uma atenção mais humanizada e criando subsídios para romper com o tecnicismo, ampliando essa proteção para todos os âmbitos da sociedade.

A participação da sociedade civil, em especial das comunidades locais, nas quais se localizam os serviços sociais públicos, é fundamental para a edificação de uma cultura de não violência e transformação das práticas que corroboram para o seu acometimento. $O$ presente estudo defende que a violência não é algo natural da condição humana, mas sim uma construção social e cultural e, desta forma, o seu efetivo enfrentamento requer a construção de novas práticas socioculturais desconstruindo com posturas que produzem e reproduzem a violência nas diversas dimensões da vida social.

Ao problematizar a construção de políticas para o enfrentamento à violência, Faleiros (2010, p.141) refere que elas ainda se situam "em contextos de descontinuidade, de burocratização, de falta de recurso e de formação de pessoal 
EM BUSCA DA INTEGRALIDADE NO ATENDIMENTO À VIOLÊNCIA SEXUAL A CRIANÇAS E ADOLESCENTES: REFLEXÕES A PARTIR DA REALIDADE DOS CREAS TOCANTINENSES

e ainda de um trabalho em redes". Nesse sentido, torna-se imprescindível que o processo de elaboração das ações de enfrentamento à violência sexual considere as particularidades desse fenômeno e seus impactos na vida das famílias.

Por isso, assevera-se que o enfoque dessa política deve ser a proteção e promoção dos direitos da criança e do adolescente sob a perspectiva da integralidade das ações. A articulação entre as políticas sociais e demais serviços do SGD tem como escopo tornar as ações mais eficazes, sendo, na atualidade, o caminho que mais apresenta efetividade social para a construção de uma política integral.

Mais do que um atendimento exclusivamente terapêutico para as crianças e adolescentes e punitivo para os/as autores/as, a integralidade no atendimento deve possibilitar bases para a construção de uma nova trajetória de vida e isso implica mudanças objetivas e subjetivas com o resgate dos direitos desses sujeitos em sua totalidade.

Propor e construir ações integradas entre as políticas sociais requer a responsabilidade dos serviços, o engajamento dos/as profissionais no compartilhamento de informações, na humanização do atendimento, e também a elaboração e discussão de fluxos e protocolos de atendimentos que visem superar a burocratização e a fragmentação das ações.

No trecho que segue, o/a profissional evidencia a acuidade da articulação do CREAS com os demais serviços para a garantia do direito à informação à população.

Então o que acontece com prevenção, articulação e mobilização são aquilo que eu te falei, são as campanhas que vêm do plano nacional. [...] o CREAS executa em conjunto com outros programas da básica e especial, então existe prevenção da forma que eu falei, palestra nas escolas, entrega de panfletos, divulgação de trabalhos, que também existe mobilização faz caminhadas, campanhas articulação com a rede então o que existe é isso, não sei te falar o que existe além disso, se tem não é repassado para a gente o que a gente faz é isso. (P1A).

A fala exprime os processos de articulação construídos pelo CREAS para a mobilização da sociedade e da própria rede de proteção, visando assim fortalecer e garantir visibilidade às ações de enfrentamento. Azambuja (2004) resgata a centralidade da municipalização das ações, o que permite ao município descentralizar a política e ampliar as discussões sobre as estratégias de atendimento às crianças e aos adolescentes.

Portanto, fortalecer a rede de proteção envolve privilegiar o planejamento e a avaliação crítico-reflexiva das ações, por meio da construção de fluxos e protocolos de atendimento que tenham a intencionalidade de prevenir a revitimização.

Outro ponto diz respeito à responsabilização do Poder Público municipal com a qualificação técnica dos/as profissionais, pois um atendimento humanizado e acolhedor somente será uma realidade concreta quando os/as profissionais desenvolverem competências teórica, metodológica, ética e política e os serviços possibilitarem ações que incidam para o rompimento e superação da violência sexual. 
A fala a seguir expressa que a construção de uma rede de proteção é um longo caminho e que são muitos os desafios postos nesse movimento.

[...] o CREAS funciona sim, assim como toda a rede aqui no município, a gente está fazendo um trabalho em equipe, não está excelente, você sabe que há falhas em qualquer local de trabalho, não há como você falar que é 100\%, mas estamos caminhando para o bom. Eu acredito que estamos e que o CREAS tem um grande papel. Acho que todo município deveria ter [...], o CRAS, por exemplo, acaba sobrecarregado por falta de CREAS [...] Acredito que esteja sendo de ótima cada profissional está tentando assim, abraçar a causa, sabe. A gente está tentando procurar, está procurando bastante assim, como eu poderia te dizer, informá-los que o trabalho existe e que proteção existe, porque eles não sabem que a proteção existe. Infelizmente, até as pessoas mais informadas, classe média, que a gente teve outro tipo de violência que foram as medidas protetivas, essas mulheres vítimas de violência doméstica não eram pessoas de classe baixa, era tudo classe média alta, classe média. Então assim, a violência ela não escolhe, questão social, ela não escolhe, ela está em todo lugar. Infelizmente, o caso do CREAS é uma, é mais difícil de acesso por ser intrafamiliar e a gente não ter como acessar, mas que está funcionando e eu acredito que vai melhorar a cada dia mais, a cada ano, eu acredito que está, que vai ficar melhor. (P1B).

O trecho extraído de uma das entrevistas é reiterativo e revelador, pois a ausência de serviços, em especial os oferecidos pelos CREAS, acarreta na sobrecarga de demandas aos/as trabalhadores/as do CRAS e entre as principais consequências disso está a não oferta de atendimento especializado. Nessa direção, o/a profissional refere que o CREAS possui centralidade tanto no atendimento quanto na mobilização e sensibilização das demais políticas sociais para atenção às situações de violência sexual.

Além disso, o/a profissional traz, em seu relato, que a violência sexual é um fenômeno transversal na sociedade, estando presente em todas as classes sociais, desmistificando, dessa forma, algumas acepções presentes em outras entrevistas que reduzem o fenômeno da violência à pobreza material das famílias.

Em um estudo estadunidense sobre a dinâmica da violência doméstica contra mulheres, desenvolveu-se, em Duluth no Estado de Minnesota/EUA, um Projeto de Intervenção ao Abuso Doméstico (DAIP), com uma metodologia para a compreensão dos fatores presentes nas situações de violência. Tais fatores são dispostos em um diagrama denominado como "Power and Control Wheel", em português, Roda de Poder e Controle (PARTNERSHIP AGAINST DOMESTIC VIOLENCE, 2006).

O modelo segue a explicação da violência contra as mulheres a partir da questão do poder e do controle. Apesar de não ser uma perspectiva nova, as interpretações do modelo de Duluth possibilitam uma clarificação conceitual e a compreensão que o poder e o controle assumem nas relações em que há presença da violência. 
EM BUSCA DA INTEGRALIDADE NO ATENDIMENTO À VIOLÊNCIA SEXUAL A CRIANÇAS E ADOLESCENTES: REFLEXÕES A PARTIR DA REALIDADE DOS CREAS TOCANTINENSES

Pope \& Ferraro (2006) referem que a Roda de Poder e Controle propicia aos/às profissionais construírem suas intervenções a partir da análise da presença de poder e controle nas relações de gênero. Além disso, nesse modelo existe também a "Equality Wheel", ou a Roda da Igualdade, nas quais são construídas as respostas profissionais diante da violência.

Apesar da Roda de Poder e Controle e a Roda da Igualdade serem um modelo utilizado em intervenções às situações de violência contra mulheres, sua forma de apreender o fenômeno pode ser também utilizado nas situações de violência sexual contra crianças e adolescentes, realizando as devidas mediações e capturando as particularidades da violência sexual contra crianças e adolescentes. A figura 1 mostra como configura-se a Roda de Poder, Controle e Sedução:

Roda de Poder, Controle e Sedução

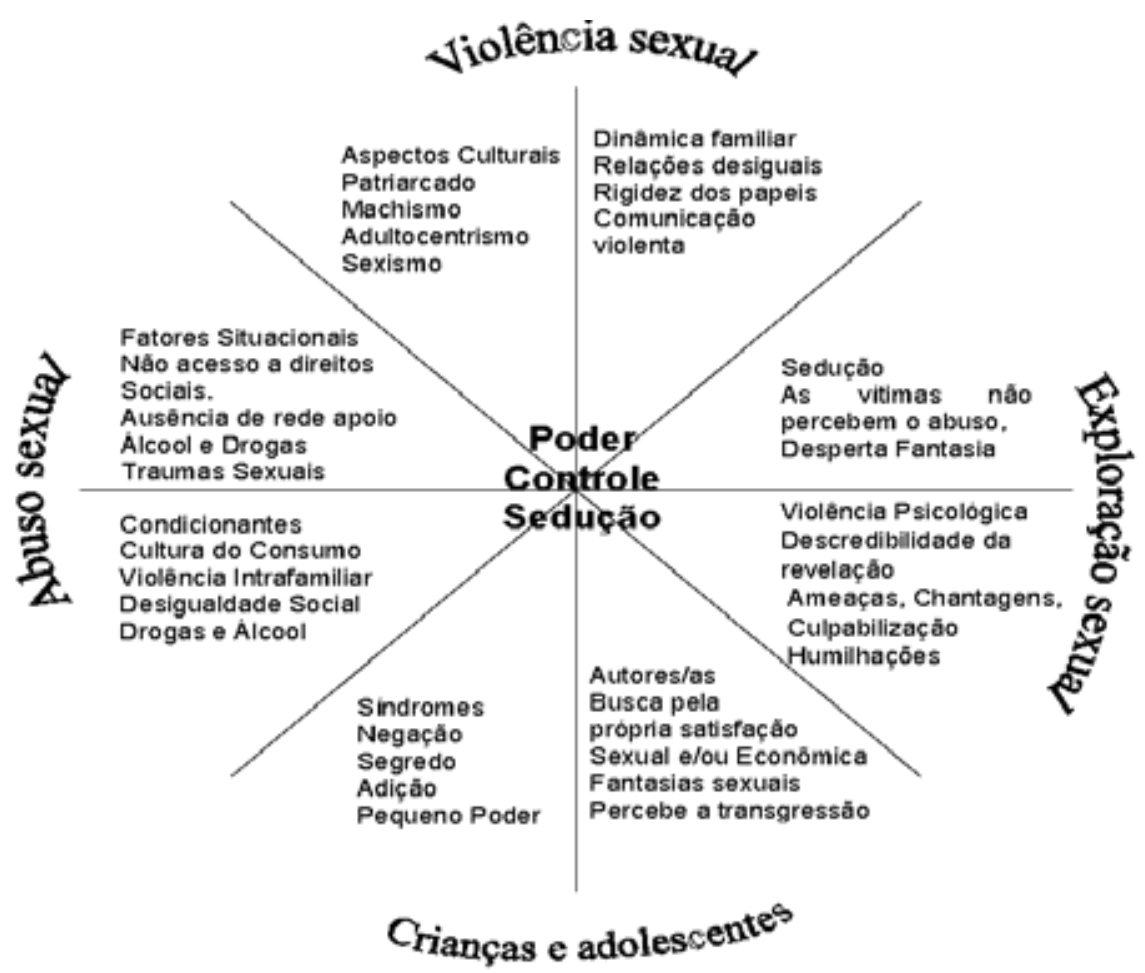

Figura 1

Fonte: Adaptação da autora.

Ampliando a perspectiva de apreensão e mediando com as particularidades da violência sexual contra crianças e adolescentes, a Roda de Poder e Controle, agora denominada de Roda de Poder, Controle e Sedução, traz elementos importantes a serem analisados e refletidos pelos/as profissionais que compõem a rede de proteção. Destaca-se que a inserção do fator sedução na roda tem relação com as reflexões desenvolvidas por Faiman (2004, p.28), que apreende esse fator como sendo um artifício amplamente utilizado pelos/ as autores/as de violência sexual, uma vez que "não há uma resistência clara à 
aproximação sexual [...] ocorre que em determinadas situações, a erotização do vínculo consiste no próprio abuso sexual".

A sedução pode ser apreendida como um fator que possibilita o controle sobre o ciclo da violência sexual, não dando chances às vítimas para romper com a violência. Salienta-se que a sedução não acomete somente as vítimas de abuso sexual, é elemento presente na exploração sexual, em que por meio da oferta do acesso a bens de consumo e promessas de "mudança de vida", muitas crianças e adolescentes acabam sendo seduzidas a um mundo de fantasias, muito distante da realidade da exploração sexual comercial.

Dentro da roda, estão expressas categorias e elementos que poderão auxiliar os/as operadores/as da rede de proteção a perceberem e planejarem suas ações a partir de uma perspectiva de totalidade. Ainda que o fenômeno seja complexo e a roda não contemple todos os fatores que engendram seu acometimento, ela serve como um importante indicador para orientar as intervenções. Reitera-se que a construção de processos interventivos com real impacto na vida das famílias que vivienciam a violência sexual em seu cotidiano, necessita que se considerem a multiplicidade de fatores, em que se destaca o poder, o controle e a sedução, presentes nas relações que perpetuam a violência sexual.

Esses três fatores contribuem para que o ciclo não seja rompido, atuando como normatizadores das relações familiares abusivas. Ressalta-se que a dinâmica da violência expressa-se em dois pólos: vitimizador e vitimizado. O poder, o controle e a sedução atuam juntamente com os demais fatores demonstrados na roda como dispositivos que garantem a perpetuação da violência sexual. Em contraponto a essa roda, apresenta-se a figura 2, a Roda da Integralidade e do Atendimento Não Revitimizante. 
EM BUSCA DA INTEGRALIDADE NO ATENDIMENTO À VIOLÊNCIA SEXUAL A CRIANÇAS E ADOLESCENTES: REFLEXÕES A PARTIR DA REALIDADE DOS CREAS TOCANTINENSES

Roda da Integralidade e do Atendimento Não Revitimizante

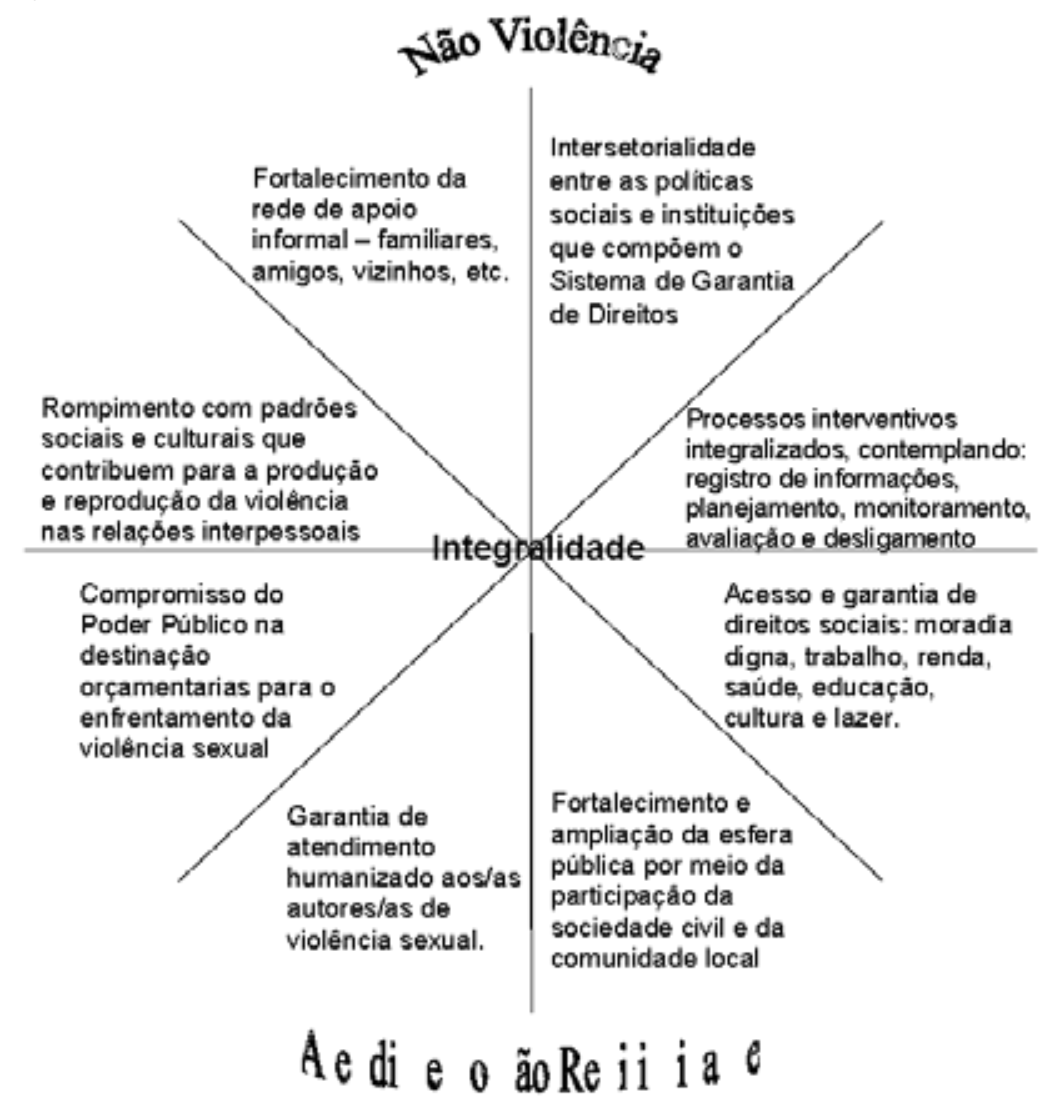

Figura 2

Fonte: Adaptação da autora.

A representação da figura 2 traz os fatores que possibilitam aos/às profissionais construírem estratégias de intervenção para o rompimento da violência sexual e promoção dos direitos humanos das crianças e adolescentes. A busca pela transformação da Roda da Integralidade, em uma realidade concreta, exige que os sujeitos da rede de proteção introduzam em seus processos interventivos novas posturas, ressignificando suas práticas.

A defesa da intersetorialidade, como fundamento para a atuação em rede no presente artigo, não remete em "transformar processos políticos, potencialmente conflituosos, em neutras prescrições administrativas" (PEREIRA, 2011, p.02). Ao contrário disso, a busca pela integralidade do atendimento remete compreender que a sinergia entre as ações é potencialidade para que o trabalho em rede não seja vislumbrado pelos sujeitos sociais como algo abstrato, mas sim como uma nova forma de prática social que é concreta, democrática e que, mesmo em constante disputa de interesses, busca desenhar novos contornos para a atenção às crianças e aos adolescentes vitimizados pelo abuso e/ou exploração sexual.

Ações integradas exigem sinergia, movimento, criatividade e conhecimento da realidade nas quais se expressam as múltiplas faces da violência sexual contra crianças e adolescentes. Historicamente, as respostas a essa violência têm 
se caracterizado pela desarticulação, setorialização e como práticas centralizadoras e hierárquicas. Os relatos dos/as entrevistados/as têm confirmado que tais aspectos estão desenhando a rede de proteção, havendo uma paradoxal coexistência entre o "discurso de proteção" e a "prática de desproteção".

\section{Conclusão}

As ações de enfrentamento, diante à complexidade da violência sexual constituem um constante desafio aos/às pesquisadores/as, profissionais, gestores/as e à sociedade em geral, uma vez que implicam na articulação das dimensões conceituais com as operacionais, das qualitativas com as quantitativas, das relacionadas à pesquisa com as de intervenção.

As discussões apresentadas, no decorrer deste artigo, são frutos da análise das entrevistas e dos prontuários de atendimento dos cinco CREAS pesquisados no Estado do Tocantins. A partir desse cenário, evidencia-se o quão desafiador vem sendo a busca pela materialização da integralidade do atendimento às crianças e adolescentes em situação de violência sexual.

Ressalta-se ainda que a interdisciplinaridade e intersetorialidade são fundamentos para o atendimento integral dos sujeitos, e também atuam como potencialidades para a construção de uma rede de proteção democrática e integrada. Assim, entende-se que a interdisciplinaridade entre as equipes técnicas e a intersetorialidade entre as políticas sociais responsáveis pela execução dos serviços e programas de proteção especial conformam uma díade que possibilita um atendimento não revitimizante na esteira da proteção integral dos direitos humanos das crianças e adolescentes.

O plano das ações sociopolíticas de enfrentamento à essa expressão da violência exige que as crianças, adolescentes e famílias sejam transformados em sujeitos políticos, havendo, portanto, um intenso estímulo e acessibilidade para a participação dessa população na construção das ações interventivas da rede de proteção. A promoção dos direitos humanos deve ser um movimento que considere as particularidades que giram ao entorno da violência sexual, considerando suas nuances e fundamentalmente as suas artimanhas que a perpetuam no cotidiano das famílias tocantinenses.

A busca pela integralidade do atendimento, a partir das falas dos sujeitos entrevistados, deve "[...] atender às demandas implícitas que se evidenciam no atendimento às vítimas e suas famílias, portanto, a política pública deve buscar, a complexidade do fenômeno da violência sexual exige um trabalho articulado e integrado". (P3C). Além disso, integralidade diz respeito à garantia de um atendimento: acolhedor, humanizado e efetivo, superando pragmatismo e posturas unilaterais de investigação e intervenção sobre a violência sexual.

As análises das entrevistas evidenciaram um "consenso discursivo e dissenso prático" (BELLINI; FALER, 2014, p. 30) entre os/as profissionais. A realidade que se revelou nas falas está muito distante das orientações técnicas da Polí- 
EM BUSCA DA INTEGRALIDADE NO ATENDIMENTO À VIOLÊNCIA SEXUAL A CRIANÇAS E ADOLESCENTES: REFLEXÕES A PARTIR DA REALIDADE DOS CREAS TOCANTINENSES

tica de Assistência Social. Os/as profissionais reconhecem que fatores como o desconhecimento do trabalho do CREAS, a precarização do trabalho e o corte orçamentário das políticas sociais são propulsores para que o enfrentamento à violência sexual materialize-se por meio de ações fragmentadas e emergenciais.

A discussão sobre as ações interventivas a partir de uma abordagem reflexiva sobre os padrões hegemônicos de resposta do Estado diante à violência sexual proporciona aos/às profissionais repensarem suas intervenções, permeando centralidade à interdisciplinaridade como prática estratégica de ampliação e articulação dos diversos saberes sem que isso acarrete na diluição das particularidades de cada profissão.

$O$ atendimento às famílias, no CREAS, deve constituir-se como um conjunto de ações, não somente no âmbito do PAEFI, mas envolvendo os demais serviços da rede de proteção, visando assim o planejamento de ações pactuadas entre os/as profissionais do CREAS e da rede de proteção, criança/adolescente e famílias, com a intencionalidade de promover processos interventivos integralizados desde o planejamento, perpassando pelo monitoramento e avaliação, até o desligamento das famílias.

Cabe ao CREAS realizar uma escuta protetiva e apreender as relações familiares na sua totalidade e a partir disso traçar os objetivos e metas do Plano Individual de Atendimento (PIA). A construção do PIA deve contar não somente com a participação dos/as responsáveis, mas também da própria criança e adolescente, entendendo que a construção coletiva possibilitará que ambos os sujeitos tenham protagonismo e atuação ativa na discussão e estabelecimento dos objetivos e metas a serem alcançados.

O acolhimento, enquanto estratégia metodológica, compreende a construção de um ambiente receptivo, respeitoso e ético por parte de toda a equipe, uma vez que as crianças, adolescentes e famílias chegam fragilizadas e necessitam encontrar, no CREAS e em sua equipe, um espaço de relações solidárias, de aproximação e de vínculos de confiança, afim de começar a construção de novas possibilidades de interação familiar e comunitária.

Nessa direção, o trabalho com as famílias não deve abranger somente a violência sexual, mesmo considerando sua centralidade, mas também estender a outros aspectos que engendram seu acometimento e superação: relações de gênero, geracionais, trabalho e geração de renda, cidadania, subjetividade social, etc.

Não há como construir uma ação sem aliar a intervenção à investigação, pois ambas são dimensões que se relacionam dialeticamente e que transbordam de possibilidades uma apreensão aprofundada da realidade social, das suas contradições e as mediações que se estabelecem e contribuem para os processos interventivos.

Assim, as situações de violência se dão no campo histórico-social, as demandas são mutáveis e o profissional tem o dever de atentar a essas variáveis (ROMEU; ELIAS; SILVA, 2014, p.178). Assevera-se que a construção de processos interventivos, capazes de ultrapassar a imediaticidade da violência sexual, exige que os/as profissionais estabeleçam conexões entre as expressões imedia- 
tas, o conhecimento teórico, as mediações da rede de proteção, mas também com o ato investigativo no sentido de identificar as múltiplas determinações e as singulares que se expressam no cotidiano.

Construir ações efetivas no âmbito da promoção, proteção e garantia dos direitos das crianças e adolescentes requer dos/as profissionais do CREAS romper com as amarras do assistencialismo e disputar politicamente nos espaços democráticos como Conselhos, Conferências e Fóruns. Notoriamente, todo esse processo de mudança não depende somente desses/as profissionais, mas sim de todos os sujeitos que atuam na rede de proteção e tal movimento exige urgentemente a ruptura com concepções conservadoras e particularistas.

$O$ atendimento integralizado não se restringe aos processos de trabalho da equipe do CREAS, a efetividade das ações do PAEFI depende profundamente das articulações com a rede de proteção. Ou seja, edificar respostas com impactos significativos na vida da população usuária requer uma rede de serviços socioassistenciais e do Sistema de Garantia de Direitos (SGD) que acolha não a violência, mas sim os sujeitos que a vivenciam.

Somente a atuação do CREAS não é suficiente para superar a violência sexual, outros mecanismos e serviços que constituem a rede de proteção deverão comprometer-se ética e politicamente com o enfrentamento a esse fenômeno. A conjuntura contemporânea desafia-nos a reinventarmos nossas práticas profissionais diante da barbárie e da desumanização do próprio ser humano.

A atual quadra histórica nos exige reflexão, mas também ousar, criar mediações que transcendam o praticismo e o imediatismo de intervenções burocráticas e mecânicas. Nossa busca consiste na garantia dos direitos humanos das crianças e adolescentes e, portanto, é momento de acolher, humanizar e lutar.

Por fim, reitera-se nas reflexões tecidas neste artigo, a importância da presença do planejamento das ações e mudança na cultura institucional das políticas e serviços sociais responsáveis pelo enfrentamento à violência sexual. A construção da integralidade do atendimento requer que a interdisciplinaridade e intersetorialidade atuem de forma articulada e conjunta.

\section{REFERÊNCIAS}

AZAMBUJA, Maria Regina Fay de. Violência Sexual Intrafamiliar: É possível proteger a criança. Porto Alegre: Livraria do Advogado, 2004.

BARDIN, Lawrence. Análise de Conteúdo. Edições Lisboa, 1977.

BELLINI, Maria Isabel Barros; FALER; Camila Susana. Intersetorialidade e Fragmentação: Partículas a Respeito. IN: BELLINI, M.I.B; FALER; C.S (orgs). Intersetorialidade e Políticas Sociais: Interfaces e Diálogos. Porto Alegre: EDIPUCRS, 2014.

BRASIL. Lei 8.069 de 13 de julho de 1990. Dispõe sobre o Estatuto da Criança e do Adolescente. Brasília, 1990 Política Nacional de Assistência Social. São Paulo: Cortez, 2004.

Tipificação Nacional dos Serviços Socioassistenciais. Resolução N 109, de 11 de novembro de 2009. Reimpressão 2013. Ministério do Desenvolvimento Social e Combate à Fome - MDS. Brasília, 2013.

FAIMAN, Carla Júlia. Abuso Sexual em Família: A violência do incesto a luz da psicanálise. São Paulo: Casa do 
EM BUSCA DA INTEGRALIDADE NO ATENDIMENTO À VIOLÊNCIA SEXUAL A CRIANÇAS E ADOLESCENTES: REFLEXÕES A PARTIR DA REALIDADE DOS CREAS TOCANTINENSES

Psicólogo, 2004.

FALEIROS, V. P. Estado e Sociedade: Parcerias e práticas contra a violência sexual. Brasília: Universa, 2010.

JUNQUEIRA, Luciano A. Prates. A gestão intersetorial das políticas sociais e o terceiro setor. Saúde e Sociedade v.13, n.1, p.25-36, jan-abr 2004.

MEKSENAS, Paulo. Pesquisa Social e Ação Pedagógica: conceitos, Métodos e Práticas. São Paulo: Loyola, 2002.

MELO, Eduardo Rezende. Crianças e adolescentes vítimas de abuso sexual: a emergência de sua subjetividade jurídica no embate entre modelos jurídicos de intervenção e seus direitos. Uma análise crítica sob o crivo históricocomparativo à luz do debate em torno do depoimento especial. IN: SANTOS, B. R; GONÇALVES, I. B; VASCONCELOS, G.; NASCIMENTO, P. B. Escuta de crianças e adolescentes em situação de violência sexual: aspectos teóricos e metodológicos: guia para capacitação em depoimento especial de crianças e adolescentes. Brasília, DF: EdUCB, 2014.

MINAYO, Maria Cecília. Violência: um problema para a saúde dos brasileiros. IN: MINAYO, Maria Cecília et.al. Impacto da violência na saúde dos brasileiros. Ministério da Saúde, Secretaria de Vigilância em Saúde. Brasília, 2007.

MOTTI, Antônio Jose; SANTOS, Joseleno. Redes de proteção social à criança e ao adolescente: limites e possibilidades. IN: MOTTI, Antônio Jose: FARIA, Thais (org). PAIR: Capacitação das redes locais - Caderno de textos. Programa de Conselhos. USAID e OIT, 2010.

NORDENSTAHL, U. C. E. Dónde está la víctima? apuntes sobre victimologia. Buenos Aires: Librería Histórica, 2008.

PARTNERSHIP AGAINST DOMESTIC VIOLENCE. "Wheels" Adapted from the Power and Control Wheel Model. Disponível em: <http://www.ncdsv.org/publications_wheel.html>. Acesso em 21 de maio de 2015.

PEREIRA, Potyara A. P. A intersetorialidade das políticas sociais numa perspectiva dialética. 2011. Disponível em: < http://matriz.sipia.gov.br/images/acervo/Texto/Potyara/intersetorialidade.pdf. Acesso em: 24 de maio de 2015.

POPE, Lucille; FERRARO, Kathleen. The Duluth Power and Control Model. 2006. Disponível em: <http:// vawresources.org/index_files/powercontrolmodel.pdf>. Acesso em: 20 de maio de 2015.

SANTIAGO, Daniela Emilena; MATTIOLI, Olga. Violência Doméstica consentida: A construção de sentidos pela criança vítima de maus tratos. IN: SANTIAGO, D. E; MATTIOLI, O.; GUIMARÃES, J. L. A Violência nos contextos familiar e social: Os desafios da pesquisa e da intervenção. Curitiba: CRV, 2009.

SANTOS, Benedito Rodrigues dos; ARAUJO, Rogério. O Enfrentamento da Exploração Sexual Infanto-Juvenil: Metodologia de Trabalho e Intervenção. Goiânia: Cânone, 2009.

VIEIRA, Monique Soares. Enfrentamento da Violência Sexual Infanto-Juvenil em Porto Alegre: contradições e perspectivas. Dissertação de Mestrado. Programa de Pós-graduação em Serviço Social. PUCRS: Porto Alegre, 2013.

. Rompendo o silêncio: O Enfrentamento da Violência Sexual Infanto-juvenil no Âmbito dos CREAS Tocantinenses. Tese de Doutorado. Programa de Pós-graduação em Serviço Social. PUCRS: Porto Alegre, 2015. 